\title{
Effect of antecedent conditions and fixed rock fragment coverage on soil erosion dynamics through multiple rainfall events
}

S. Jomaa ${ }^{a,{ }^{*}, 1}$, D.A. Barry ${ }^{\text {a }}$, B.C.P. Heng ${ }^{\text {b,2 }}$, A. Brovelli ${ }^{\text {a }}$, G.C. Sander ${ }^{b}$, J.-Y. Parlange ${ }^{\text {c }}$

${ }^{\text {a }}$ Laboratoire de technologie écologique, Institut d'ingénierie de l'environnement, Faculté de l'environnement naturel, architectural et construit (ENAC), Station 2, Ecole Polytechnique Fédérale de Lausanne (EPFL), 1015 Lausanne, Switzerland. Ph. +41 (21) 693-5576; +41 (21) 693-5919; Fax. +41 (21) 693-8035. E-mail addresses: andrew.barry@epfl.ch, alessandro.brovelli@epfl.ch

${ }^{\mathrm{b}}$ Department of Civil and Building Engineering, Loughborough University, Loughborough LE11 $3 T U$ United Kingdom. Ph. +44 (1509) 223-777; Fax. +44 (1509) 223-981. E-mail address:

g.sander@lboro.ac.uk

${ }^{\mathrm{c}}$ Department of Biological and Environmental Engineering, Cornell University, Ithaca, New York 148535701 USA. Ph. +1 (607) 255-2476; Fax. +1 (607) 255-4080. E-mail address: jp58@cornell.edu

Accepted by Journal of Hydrology, January 2013

*Author to whom all correspondence should be addressed

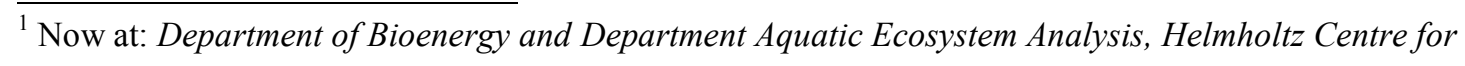
Environmental Research - UFZ, Brueckstrasse 3a, 39114 Magdeburg, Germany. Ph. +49 (391) 810-9135; Fax. +49 (391) 810-9699. E-mail address: seifeddine.jomaa@,ufz.de

${ }^{2}$ Now at: Building Research Institute, Housing and Development Board, 480 Lorong 6 Toa Payoh 310480, Singapore. Ph.+65 6490-2663; Fax. +65 6490-2662. E-mail address: peterheng@e.ntu.edu.sg 


\section{Abstract}

The effect of antecedent conditions and specific rock fragment coverage on precipitation-driven soil erosion dynamics through multiple rainfall events was investigated using a pair of $6-\mathrm{m} \times 1-\mathrm{m}$ flumes with 2.2\% slope. Four sequential experiments - denoted E1, E2, E3 and E4, involved 2-h precipitation (rates of $28,74,74$ and $28 \mathrm{~mm} \mathrm{~h}^{-1}$, respectively) and $22 \mathrm{~h}$ without rainfall - were conducted. In each experiment, one flume was bare while the other had $40 \%$ rock fragment coverage. The soil was hand-cultivated and smoothed before the first event (E1) only, and left untouched subsequently. Sediment yields at the flume exit reached steady-state conditions over time scales that increased with sediment size. Experiments were designed such that both steady and non-steady effluent sediment yields were reached at the conclusion of E1. Results from subsequent experiments showed that short-time soil erosion was dependent on whether steadystate erosion was achieved during the preceding event, although consistent steady-state effluent sediment yields were reached for each sediment size class. Steady-state erosion rates were, however, dependent on the rainfall intensity and its duration. If steady-state sediment yields were reached for a particular size class, that class's effluent sediment yield peaked rapidly in the next rainfall event. The early peak was followed by a gradual decline to the steady-state condition. On the other hand, for size classes in which steady state was not reached at the end of the rainfall event (i.e., E1), in the following event (E2), the sediment yields for those classes increased gradually to steady state, i.e., the sharp peak was not observed. The effect of rock fragment cover $(40 \%)$ on the soil surface was also found to be significant in terms of the time to reach steady state, i.e., their presence reduced the time for steady conditions to be attained. Effluent sediment yields for the bare and rock fragment-covered flumes (E1) showed steady conditions were reached for the latter, in contrast to the former. We used the Hairsine-Rose (H-R) model to simulate the experimental data as it explicitly models soil particle size classes. Experiments E1 and E2 involved soil compaction by raindrops, and in this case the model predictions were found to be unsatisfactory. However, compaction was effectively completed by the end of experiment E2, and the model provided reasonable predictions for experiments E3 and E4.

Keywords: Hairsine and Rose model, Sediment yield, Steady-state development, Multiple rainfall events, Initial conditions, Laboratory flume 


\section{Introduction}

Soil erosion is influenced by several interacting factors, including rainfall intensity, soil properties, topography, land cover, spatial scale, and initial and antecedent soil conditions (Hancock et al., 2008; Neave and Rayburg, 2007; Rudolph et al., 1997). Surface sealing and crusting also play an important role. These are differentiated by their moisture content; seals are wet while crusts are dry (Singer and Shainberg, 2004). Their effect is decrease the infiltration rate, thereby increasing runoff and potential for soil loss (e.g., Le Bissonnais et al., 1998; Neave and Rayburg, 2007).

When aggregates are broken down by raindrop impact and/or slaking processes, the disaggregated particles are deposited within soil pore spaces forming a thin, low permeability surface layer (Assouline, 2004). Furthermore, when soil with low moisture content experiences a rain event, there is enhanced aggregate slaking and breakdown due to air escape upon rapid wetting. This enhances soil detachment by raindrop impact and subsequent transport by overland flow (Le Bissonnais et al., 1989; Römkens et al., 2002; Rudolph et al., 1997).

While initial moisture content during individual storms affects soil erosion delivery, the soil water regime over longer periods includes repeated wetting-drying cycles that also influence erodibility producing considerable uncertainty in event-based erosion predictions (Bryan, 2000; Fohrer et al., 1999; Le Bissonnais and Singer, 1992). Luk et al. (1993) showed that soil loss reduced over successive storms due to the formation of a cohesive crust during the drying cycles. Furthermore, Mamedov et al. (2006) highlighted that antecedent moisture content and soil surface aging (i.e., wetting and keeping the soil at given moisture content) affect the seal formation and erosion rate. Consequently, the antecedent soil conditions affect the surface soil structure differently, which in turn affects soil erosion. Although the interactions between rainfall intensity, antecedent soil conditions and the surface sealing have been investigated previously, quantitative 
information about the effects of those interacting processes on soil erosion and sediment yield is limited (Kuhn et al., 2010; Römkens et al., 2002).

Rock fragment cover affects both the hydrological response and soil erosion (Jomaa et al., 2012b, 2012c; Poesen et al., 1990, 1994; Rieke-Zapp et al., 2007). Surface rock fragments delay the time-to-runoff and prevent surface sealing, resulting in decreased runoff generation and an increased infiltration rate into the soil, which in consequence reduces the erosion delivery. Jomaa et al. (2012b) showed, using different rock fragment coverages (fragments were arranged regularly on top of the soil) in controlled laboratory flume experiments, that raindrop detachment is proportional to the effective rainfall and the area of exposed soil, other factors being equal (antecedent moisture content, bulk density and surface roughness). They found that, to a lesser extent, this relationship is also controlled by the initial moisture content and bulk density of soil. Nevertheless, other studies reported that rock fragments can lead to different soil erosion outcomes depending on their characteristics (cover, size and emplacement) (Jomaa et al., 2012c; Loosvelt, 2007). Jomaa et al. (2012c) showed that rock fragments affect the soil particle size classes differently, depending on the time scale of the erosion event.

The experiments reported herein focus on the temporal response of the soil's individual sediment size classes under a sequence of rain events. A formulation that accounts explicitly for the transport of different size classes is the Hairsine and Rose (H-R) soil erosion model (Hairsine and Rose, 1991). The H-R model incorporates a mechanistic description of the shielding effect of eroded soil that forms the deposited layer on top of the parent soil, which built on the earlier work of Rose et al. (1983a, 198b). The H-R model predictions were compared favourably with experimental data for single rainfall events (Heng et al., 2011; Jomaa et al., 2010; Proffitt et al., 1991; Rose et al., 2007; Sander et al., 1996, 2007; Tromp-van Meerveld et al., 2008). Here, we test the ability of H-R model to predict the details of sediment yields of different size classes 
through multiple rainfall events and in the presence of a rock fragment cover. The experiments involve soils that initially undergo rapid sealing/compaction, followed by a relatively stable condition, giving the opportunity to check the model's performance during this transition.

Specifically, the aims of this study were to investigate, in a laboratory flume and at the level of individual sediment size classes, (i) the effect of antecedent conditions and (ii) specific rock fragment coverage on soil erosion yields under multiple erosion events. In addition, the data set provides (iii) an opportunity to assess the ability of the H-R model to predict soil erosion dynamics under multiple rainfall events for a soil undergoing compaction.

\section{Methods}

\subsection{Experimental setup}

Four simulated rainfall events were conducted on successive days using the EPFL erosion flume (Baril, 1991; Viani, 1986). Descriptions of the indoor flume (6-m $\times 2-\mathrm{m}, 2.2 \%$ slope) and rainfall simulator are given elsewhere (Jomaa et al., 2010; Tromp-van Meerveld et al., 2008). A summary of the experimental conditions and characteristics of each individual event is reported in Table 1. A low precipitation-rate rainfall event $\left(28 \mathrm{~mm} \mathrm{~h}^{-1}\right)$ was followed by two events with the same high precipitation rate $\left(74 \mathrm{~mm} \mathrm{~h}^{-1}\right)$, and again by one with the same low precipitation rate as the first event.

The duration of each rainfall event was $2 \mathrm{~h}$ and was followed by $22 \mathrm{~h}$ of natural air-drying without altering the soil surface. The flume was divided into two identical 1-m wide flumes by installation of a thin, vertical barrier. Flume 1 was kept with bare soil. The same soil was used in flume 2 except that $40 \%$ of its surface was covered by rock fragments. Before the first precipitation event (E1), the soil was hand-cultivated to a depth of $20 \mathrm{~cm}$ and then mechanically smoothed. Flume 2 was covered by a uniform, triangular pattern of rock fragments placed on the 
surface (not embedded in the soil matrix). Before the commencement of precipitation, both flumes were gently pre-wetted using a sprinkler (Table 1 reports the volumetric initial moisture content). More experimental details can be found in Jomaa (2012a). Note that identification of the erosion events was slightly changed compared with our previous work (Jomaa et al., 2012a). The label "H7” was removed resulting in four sequential rainfall events denoted E1, E2, E3 and E4 rather than H7-E1, H7-E2, H7-E3 and H7-E4, respectively. An agricultural loamy soil from Sullens, Switzerland, was used. Its particle size distribution is reported in Table 2, with a detailed description of its properties given by Baril (1991). For all experiments, visual inspection showed there was no rill formation, so raindrop detachment was the dominant erosion process. The absence of rills is consistent with stream power calculations (Jomaa et al., 2010). Experiment E3 had the higher runoff rate (Table 1$)$ and in consequence the highest stream power estimate $(0.02$ $\left.\mathrm{W} \mathrm{m} \mathrm{m}^{-2}\right)$, which is much lower than the critical stream power $\left(0.15 \mathrm{~W} \mathrm{~m}^{-2}\right)$ value required for rill erosion of loamy soils (Beuselinck et al., 2002).

Table 1 near here

Effluent discharge samples were used to determine discharge rates and sediment yield rates. Samples were analysed to quantify the total sediment yield and the sediment yields of seven size classes $(<2,2-20,20-50,50-100,100-315,315-1000$ and $>1000 \mu \mathrm{m})$. Larger size classes (larger than $100 \mu \mathrm{m})$ were sieved, while for the finer particles $(2-100 \mu \mathrm{m})$ the laser diffraction technique was employed (Jomaa et al., 2010).

Table 2 near here

\subsection{Modelling}

Measured sediment yields were analysed using the H-R erosion theory. Model assumptions and governing equations have been described and analysed previously (e.g., Barry et al., 2010; 
Hairsine and Rose, 1991; Heng et al., 2009; Hogarth et al., 2004; Lisle et al., 1998; Parlange et al., 1999; Rose et al., 1983a, 1983b; Sander et al., 2007). Jomaa et al. (2012c) accounted for the effect of rock fragment coverage using an additional parameter, $\eta$, which is the fraction of soil surface exposed (i.e., not covered by rock fragments). Sander et al. (1996) presented an analytical solution to the H-R model that agreed well with data obtained using different laboratory flume experiments with a gentle slope, regular topography and under homogenous rainfall (e.g., Jomaa et al., 2010, 2012c; Proffitt et al., 1991; Tromp-van Meerveld et al., 2008). Their analytical solution is used in the analysis presented below.

\section{Results}

\subsection{Laboratory flume experiments}

\subsubsection{Event E1}

This rainfall event was presented and discussed by Jomaa et al. (2012b, 2012c) and the observations drawn are only summarized here. Results revealed that the rock fragments affected the flume's hydrological behaviour as well as the erosion rates. The greater time-to-runoff and smaller flow discharge in flume 2 (Table 1 and Fig. 1) showed that the surface rock fragments increased the infiltration rate in the soil, which in turn retarded runoff generation. Visual observations and moisture content measurements suggested that the additional infiltration occurred near and beneath the rock fragments. Because the soil was hand-cultivated before E1 commenced, raindrop-driven compaction took place wherever the soil was exposed to precipitation. It was hypothesized that rock fragments protect the soil surface from rainfall, and therefore reduce soil sealing by raindrops.

\section{Figure 1 near here}

The initial sediment yield peak was reached at different times in the two flumes, viz. 8 and 15 
min since start of runoff for flumes 1 and 2, respectively. The rock fragment cover also reduced erosion rates, resulting in considerably lower soil loss from flume 2 . The sediment yield rates collected on the two flumes behaved similarly, with an early time peak that gradually declined towards steady values (Fig. 2). For flume 1, during the experiment only the sediment yield of fine particles (diameter $\leq 20 \mu \mathrm{m})$ reached steady state. Note that we use an operational definition of steady state, which is said to occur when sediment yields show little change with time relative to the change in sediment yields evident in the experiments - true steady state does not occur until sediment yields of all sediment size classes are unchanging. For the medium and larger size classes, it was clear that steady soil loss in the flume effluent was not reached by the end of the experiment. On the other hand, in the rock fragment-covered flume (flume 2), results suggest that steady state was achieved for all size classes (or nearly so), except the coarsest class where the data show a high level of scatter. This could be explained by the fact that the surface rock fragments decreased the cross-sectional area, increasing further the water depth compared with the bare soil conditions. This increased depth of water attenuated raindrop-driven erosion and permitted earlier attainment of steady-state sediment yields rates in the effluent.

\section{Figure 2 near here}

\subsubsection{Event E2}

Similar to E1, time-to-runoff was greater for flume 2 (with rock fragments) than for flume 1 (bare soil), and the steady-state discharge was less, consistent with greater infiltration in flume 2. The steady-state infiltration rates for E2 were significantly lower than for E1 (Table 1) due to soil compaction. The decrease was more pronounced for bare soil conditions, with a reduction to about a third of the initial value ( 7.5 vs. $\left.2.6 \mathrm{~mm} \mathrm{~h}^{-1}\right)$, whereas for the rock fragment-protected soil the infiltration in E2 was about $80 \%$ of that measured during the first event (13.4 vs. $10.2 \mathrm{~mm} \mathrm{~h}^{-1}$ ). Besides the compaction due to raindrops that occurred during E1, this suggests that the decreased 
infiltration was due to the formation of a surface crust during the 22-h drying period preceding E2. The presence of rock fragments protected the soil surface from direct raindrop impact and consequent compaction.

Concerning sediment erosion, the two flumes showed different patterns (Fig. 3). In flume 1, the total sediment yield had an earlier peak just after the onset of runoff (with a maximum value around $5.6 \mathrm{~g} \mathrm{l}^{-1}$ ), followed by a rapid decline to a minimum erosion rate of $3.6 \mathrm{~g} \mathrm{l}^{-1}$ at about 8.2 min since the start of runoff. Following this minimum, the soil loss rose gradually to reach a steady-state value of around $5.5 \mathrm{~g} \mathrm{l}^{-1}$ after about $42.2 \mathrm{~min}$ after runoff commenced (Figs. 1 and 3). The same pattern was observed for the fine-to-medium sediment size classes (up to $100 \mu \mathrm{m}$ ), although it was pronounced only for the medium size class $(50-100 \mu \mathrm{m})$. Larger particles (diameter $>100 \mu \mathrm{m}$ ) did not show the early peak but a slow increase towards the steady-state sediment yield. The relative composition of the discharged sediments changed over time: Initially, the fine and medium size classes were dominant, whereas towards the end of the experiment the contribution of larger classes increased. A possible interpretation of the short-time minimum is that, in addition to surface crusting, some relatively loose (previously eroded and deposited) dry material was present on the soil surface, which was removed relatively easily. Following removal of this loose material, the compacted/sealed surface layer was eroded more gradually. The data show clearly that the finer and coarser grains sizes responded differently, since the initial sediment yield peak vanishes for the larger size classes (100 $\mu \mathrm{m}$ and larger). It was already observed that these sediment classes were not at steady state at the end of E1, which apparently led to "trapping" of these sediments during the drying period. Without further investigation, it is not possible to make precise interpretations of the mechanism of this "trapping", but one possibility is that the initial erosion/deposition process leads to a sediment-size differentiated profile at the soil surface.

The total sediment yields for the rock fragment-covered flume showed an early peak that 
declined gradually to steady-state sediment yields in the range 3-3.5 $\mathrm{g} \mathrm{l}^{-1}$ (Fig. 1). The surface rock fragments increased the early peak soil loss compared with flume $1\left(7.8 \mathrm{vs} .5 .6 \mathrm{~g} \mathrm{l}^{-1}\right)$ and reduced the steady-state erosion rates. This suggests that erodibility of flume 2 was larger than flume 1, probably because flume 2 experienced less compaction/sealing than flume 1 . The sediment breakthrough curves for all individual size classes consistently showed an early peak followed by a rapid decline to steady-state sediment yield rates, except perhaps for the largest size classes ( $>$ $1000 \mu \mathrm{m})$. Even for this size class, a similar trend was observed, despite the scatter in the data (Fig. 3). Again, there is evidence of a short-time minimum in the effluent erosion rates for all except for the largest size classes.

To summarize, all size classes for the rock fragment-covered flume showed consistent behaviour, except the largest class, with high initial sediment yields decreasing to steady-state erosion rates. Flume 1, however, had more complex behaviour. For the smaller size classes, soil loss trends were similar to those in flume 2 (high initial erosion rate followed by a rapid decline), albeit with different magnitude and a clear short-time minimum. For the larger size classes, sediment yield rates were initially very low, and increased gradually to steady-state values. This significant difference is due to the attainment (or not) of steady-state erosion rates during E1.

\section{Figure 3 near here}

Comparison of sediment yields for E1 and E2 provides insights into the dependency of erosion rates to antecedent and initial soil conditions and rainfall intensity. The initial sediment yield for E1 from flume 1 (bare soil, Fig. 1) was smaller than the initial loss from the same flume during E2 $\left(5.6<8.2 \mathrm{~g} \mathrm{l}^{-1}\right)$, despite the larger rainfall rate utilized in E2. This was due to changes in soil properties, which decreased the erodibility of the surface. After about 40-50 min following the start of runoff, the total sediment yield rate of E2 exceeded that of E1, due to the precipitation intensity. At steady state, the difference in total sediment loss between the two rainfall events was 
larger for the bare-soil flumes (5.5 vs. $3.5 \mathrm{~g} \mathrm{l}^{-1}$ collected from E2 and E1, respectively) compared with rock fragment-protected flumes $\left(3.5>2.5 \mathrm{~g}^{-1}\right.$ collected from E2 and E1, respectively). This difference results from a combination of factors. The flow depth on flume 2 was greater than that on flume 1 due to the reduction of the flow cross-sectional area and the greater resistance offered by surface rock fragments (Table 1). Also, the steady infiltration rate was greater on flume 2 , which would have increased sediment deposition relative to flume 1 (Table 2).

For the individual size classes, results (Figs. 2 and 3) showed that, at short time, in both flumes the two finer size classes $(<2$ and 2-20 $\mu \mathrm{m})$ were more eroded in E1 than E2, whereas the medium and the larger size classes were more eroded during E2. At long times, the sediment loss of all individual size classes measured in E2 were greater than in E1 except for the two finest size classes, which had very similar steady-state erosion rates. These results highlight that the early soil erosion response is more affected by the initial and antecedent soil conditions (water moisture content and surface sealing) than the rainfall intensity. As the precipitation continued, however, this early-time effect reduced gradually and the eroded sediment yields showed differences that would be expected due to the differences in rock fragment coverage (comparing flumes 1 and 2 in E2) and effective rainfall rates (comparing E1 and E2).

\subsubsection{Event E3}

Event E3 followed E2 after $22 \mathrm{~h}$ of natural air-drying, and with the same precipitation rate. Observe that the sediment yields had reached steady state by the conclusion of E2 for most size classes. Steady-state infiltration rates were reduced for both flumes compared with E2 (Table 1). The decrease was larger for the rock fragment-protected soil than for the bare soil (about 25\% and $40 \%$ decrease for the flume 1 and 2, respectively). For both flumes, the initial and final moisture contents and the time-to-runoff were also similar between E2 and E3 (Table 1). Therefore, it is likely that both flumes had reached a similar rainfall-compacted state before the completion of E2, 
and thus the exposed areas in each flume would have had the same hydraulic conductivity and the same initial moisture content at the start of E3. For flume 2, however, the rock fragments still acted to protect the underlying soil from raindrop impact and the resulting compaction.

\section{Figure 4 near here}

The total sediment breakthrough curves of the two flumes (Fig. 4) show similar patterns, with lower measured soil losses in flume 2. Total sediment yield rates collected from flume 1 show a large early peak of $10.8 \mathrm{~g} \mathrm{l}^{-1}$ followed by a rapid decline (after about $10 \mathrm{~min}$ following the start of runoff) towards a steady-state sediment yield of about $5.5 \mathrm{~g} \mathrm{l}^{-1}$ (Fig. 4). However, for the rock fragment-covered flume, the total erosion rates peaked at $4.3 \mathrm{~g} \mathrm{l}^{-1}$, and then declined rapidly to a steady-state sediment yield of $3 \mathrm{~g} \mathrm{l}^{-1}$. Compared with the bare flume, the rock fragments reduced the soil erosion in both short and long times. Results showed that, in flume 2, the infiltration rate was three times greater compared with bare soil conditions, enhancing the deposited mass of all size classes, which in turn reduced the erosion rate.

Erosion rates of individual size classes collected from flumes 1 and 2 followed the same behaviour as that for the total sediment yields (Fig. 4). The steady-state soil losses obtained in events E2 and E3, which were conducted using the same precipitation rate $\left(74 \mathrm{~mm} \mathrm{~h}^{-1}\right)$, were similar. However, the short-time response differed greatly (Figs. 3 and 4). We conclude that, at the end of E1, the soil state differed to that at the end of E2, leading to the different short-time responses. Additionally, it seems that the presence of rock fragments in E3 reduced the early peak of all individual size classes compared with the corresponding classes observed in the same flume during E2.

For flume 1, the sediment yield rates of the two finest size classes were slightly higher in E2 than E3 throughout the experiment (Figs. 3 and 4). In contrast, the sediment yield of the mediumsize class $(20-50 \mu \mathrm{m})$ was slightly greater in E3 than in E2 only in terms of the short-time 
behaviour of the erosive event. The larger size classes (larger than $50 \mu \mathrm{m}$ ) were notably more eroded in E3 than in E2 at short times. However, they were eroded similarly over longer periods. For the rock fragment-covered flume, the sediment breakthrough curves obtained for all the individual size classes were slightly less eroded in E3 than E2 during the short-time behaviour. In terms of longer periods, however, results showed that all size classes appeared to have eroded identically during both events.

\subsubsection{Event E4}

The measured time-to-runoff observed in E4 $\left(28 \mathrm{~mm} \mathrm{~h}^{-1}\right)$ was slightly greater than was observed in the previous event $\left(\mathrm{E} 3,74 \mathrm{~mm} \mathrm{~h}^{-1}\right)$, reflecting the effect of rainfall intensity on the time-to-runoff. The steady-state infiltration rates during E4 were less than those in all other experiments. Possible reasons for this are (i) continued slow compaction/sealing of the soil and (ii) lower overland flow depth leading to a lower vertical head gradient driving infiltration.

Results collected during E4 showed consistently that rock fragment cover reduced the soil erosion delivery (Fig. 5). Rock fragments reduced considerably the sediment yields of the finer and the mid-size classes (up to $100 \mu \mathrm{m}$ in diameter) compared with the bare soil flume. The rock fragments had less effect on the larger size classes $(100-315$ and 315-1000 $\mu \mathrm{m})$. For these, the rock fragments reduced the short-time soil losses. For longer times, despite the scatter the data suggest that sediment yields from the rock fragment-covered flume were lower than for the bare soil.

The short-time erosion rates in both flumes showed similar behaviour to those in E3 - an early peak followed by a rapid decline to steady state - except for the largest size class $(>1000 \mu \mathrm{m})$ where the data are scattered. During E4, all individual size classes have lower erosion yields than in E3 for both flumes due to the different precipitation rates (Figs. 4 and 5). 
E1 and E4 had the same rainfall intensity, and contrast the effect of different initial conditions, wetting-drying cycles and precipitation history on erosion rates. Not surprisingly considering the compaction/sealing that occurred since the initial preparation of E1 and the much greater initial moisture content in E4, the time-to-runoff for E1 was much greater than that for E4 (Table 1). The different initial conditions used between these two experiments affected greatly the cumulative discharge (Table 1), which in turn affected the cumulative eroded mass. For bare soil conditions, the cumulative discharge doubled from E1 to E4. The cumulative eroded mass, however, reduced during the event E4 compared with the event E1. Considering the different initial conditions in E1 and E4 (dry and hand-cultivated soil against wet and compacted soil, respectively), it is clear that total sediment yield during an erosive event is strongly influenced by the antecedent conditions, especially the soil compaction.

For rock fragment-covered soil the cumulative discharge measured in E4 increased more than five times compared with E1 (Table 1). The observed cumulative eroded mass during E4 increased slightly compared with E1. In contrast to experiments E1 and E4 (both conducted with a precipitation rate of $28 \mathrm{~mm} \mathrm{~h}^{-1}$ ), E2 and E3 have roughly the same cumulative discharge as well as eroded mass (Table 1). This could be explained by the dissimilarity between experiments E1 and E4 (compared with E2 and E3) in terms of initial moisture content and, particularly, surface compaction.

$$
\text { Figure } 5 \text { near here }
$$

\subsection{Modelling}

According to the H-R theory, sediment dynamics are controlled by (i) the detachability of the original soil $(a)$ and of the shield layer $\left(a_{d}\right)$, (ii) the degree of protection of the original soil ensured by the re-deposited sediment, which is controlled by the deposited mass per unit area 
needed to shield the original soil completely $\left(m_{t}^{*}\right)$ and (iii) the settling velocity of each sediment class $\left(v_{i}\right)$. In the following model application, settling velocities were taken from Tromp-van Meerveld et al. (2008), who used the same soil as in this study, and adjusted within a defined range as reported in Table 3 (Jomaa et al., 2010, 2012c). The H-R model assumes that particles are suspended into the overland flow, and then settle back to the bed at a rate that varies with their settling velocity, ignoring other soil erosion processes during the erosive event.

The H-R model was fitted to each set of experimental data, during which the three model parameters $a, a_{d}$ and $m_{t}{ }^{*}$ were calibrated. As was the case previously (Jomaa et al., 2010, 2012c), the values were initially adjusted manually until a reasonable fit was found, and then an automated estimation procedure was applied. This optimization technique was implemented based on the minimization of the least-squares objectives function using a derivative-free simplex search method (Jomaa et al., 2010).

Following Jomaa et al. (2010, 2012c), the fitting procedure priority was given to reproduce the two finer classes $(<2$ and $2-20 \mu \mathrm{m})$, as they have the larger proportion of the eroded sediments (Table 2). In addition, we found in earlier experiments using the same flume that the H-R model produces more accurate results for the finer size classes (e.g., Jomaa et al., 2010; Tromp-van Meerveld et al., 2008). For the model application, a single overland flow depth value, $D$, is needed, which was determined as an average from the long-time behaviour (Sander et al., 1996). Tables 3 and 4 give the parameters used in the H-R model for each rainfall event. The model evaluation index (correlation coefficients $r^{2}$ ) were determined separately for the finer $(<2,2-20$ and $20-50 \mu \mathrm{m}$ ) and larger (up to $1000 \mu \mathrm{m}$ ) size classes, except the largest size class, which displayed significant scatter (Table 4).

Initially, raindrops detach sediment directly from the soil surface, which is unprotected by the water depth, generating high effluent sediment yields at the commencement of runoff. Thus, 
measured initial sediment yields were used as the initial conditions for the model application to all rainfall events. In addition, the initial deposited mass of the individual size classes on the soil surface, for each rainfall event, were taken from the predicted mass of the corresponding classes at the conclusion of the previous event, except for E1, which was conducted with hand-cultivated soil and zero initially deposited mass was specified for all individual size classes. In terms of longtime behaviour, the effluent particles size distribution was different than the parent soil. As discussed by Jomaa et al. (2012c), this might result from aggregate breakdown (Legout et al., 2005), which is not considered in the H-R model. To reproduce this behaviour, in the model application for all events the size class fractions were deduced from the measured effluent sediment yields over the end of the event (Table 2).

\subsubsection{Event E1}

Since Jomaa et al. (2012c) discussed modelling of this experiment (Fig. 2), only a summary is given here. The overland flow depths used for the fitting procedure were 3 and $4 \mathrm{~mm}$ for flumes 1 and 2, respectively. The size classes proportions used in the model application of this event were taken from the observed sediment distribution during the final 10 min of the experiment although the stationary phase had not been fully developed for the bare soil conditions (Fig. 2).

Consistently for flumes 1 and 2, the model was able to represent reasonably $\left(r^{2}>0.84\right)$ the observed sediment yields of the finer materials $(<2,2-20$ and 20-50 $\mu \mathrm{m})$. However, the model could not provide close predictions of the erosion rates of the rest of the size classes and, in consequence, the total sediment yield (Fig. 2). For the duration of this rainfall event, soil compaction took place, leading to surface morphological changes as well as changes in detachability of soil particles. Steady-state behaviour would not result until these changes stabilised, which also would account for the poorer model performance compared with subsequent events. 


\subsubsection{Event E2}

Modelling of E2 took into account results from E1. The H-R model could not predict the measured sediment yields during E2, when the same estimated parameters as in E1 were maintained. When each flume in E2 was fitted separately, however, model predictions improved. Compared with the previous event, for bare-soil conditions (flume 1), slightly reduced values for $a$ and $a_{d}$ were found (Table 4). However, for the rock fragment-covered flume (flume 2), the values of $a$ and $a_{d}$ were reduced significantly compared with the corresponding values found for E1 (Table 4). The mass per unit area needed to protect the original soil, $m_{t}^{*}$, was the same in each flume for E2, and is double that used in E1 (Table 4). The increase of $m_{t}^{*}$ is consistent with the increased rainfall intensity as found by Jomaa et al. (2012c). Moreover, in order to fit the individual sediment yields of flumes 1 and 2, two sets of settling velocities were used (Table 3).

For flume 1, the H-R model predicted the erosion rates of the finer size classes $(<2,2-20$ and $20-50 \mu \mathrm{m})$ reasonably well $\left(r^{2}>0.71\right.$, Fig. 3$)$. For the mid-size class $(50-100 \mu \mathrm{m})$, the model could predict only the steady-state behaviour. For the larger particles $(>100 \mu \mathrm{m})$, the model reproduced the steady-state behaviour well (Fig. 3), but it overestimated the initial contributions of these size classes to the total sediment yield, generating a short-time over-prediction in the total sediment yield.

For the rock fragment-covered flume, the model reproduced the measured erosion rates of all individual size classes successfully $\left(r^{2}>0.85\right)$, except for the short-time behaviour of the largest size class $(>1000 \mu \mathrm{m})$, generating a slight underestimation in the total sediment yield.

\subsubsection{Event E3}

With the same values of $a_{d}$ and $m_{t}^{*}$ that were used in event E2 (same precipitation rate as E3), 
the model reproduced the total and the individual size classes observed in flumes 1 and 2 during E3 reasonably well (Fig. 4). However, close model predictions were obtained only when the value of $a$ was reduced in both flumes compared with the corresponding flumes during event E2 (Table 4). The reduction in the $a$ value is due a decrease in the contribution of the original soil to the soil erosion delivery due to the development of the surface sealing during the previous events (E1 and E2). In addition, results showed that soil erosion behaviour observed over the course of this experiment was similar to that found in the rock fragment-covered flume during the previous event (E2), i.e., a short-time peak followed by a rapid exponential decay to steady-state sediment yield. Thus, the same sets of settling velocities were used for the rock-covered flumes for both events E3 (Table 3) and E2. For both flumes, the predicted sediment yields reproduce well the measured erosion rates of all size classes, except for the largest size class $(>1000 \mu \mathrm{m})$. This latter was underestimated, which in turn generates an underestimation in the total sediment yield, particularly for bare soil conditions (Fig. 4).

\subsubsection{Event E4}

In E4, the precipitation rate was lowered to $28 \mathrm{~mm} \mathrm{~h}^{-1}$ from $74 \mathrm{~mm} \mathrm{~h}^{-1}$ in E3. The average overland flow depths used for the model fitting of flumes 1 and 2, were 4 and $5 \mathrm{~mm}$, respectively (Table 4). Consistent with the previous events, the detachability of the original soil, $a$, decreased further for both flumes (Table 4), reflecting that sealing developed over the course of the experiments. The same detachability coefficient of the shield layer, $a_{d}$, as in the previous event E3 was used. The value of $a_{d}$ used in this event was less than the half that used in E1, although both experiments were conducted with the same rainfall intensity $\left(28 \mathrm{~mm} \mathrm{~h}^{-1}\right)$. In contrast to $a_{d}$, the same value of $m_{t}^{*}$ was used as in E1. This suggests that the mass per unit area needed to complete the shield layer depends more on rainfall intensity than other factors, as also observed by Jomaa et al. (2012c). The model was able to represent satisfactorily the measured sediment yields of the 
finer for both flumes 1 and 2 with $r^{2}$ values greater than 0.67 and 0.80 , respectively. In addition, the model reproduced reasonably the total sediment yield for both flumes, even though the slight underestimation of the larger size classes $(100-1000 \mu \mathrm{m})$. However, the model did not provide an accurate prediction of the largest size class in flumes 1 and 2, where considerable scatter appeared in the data (Fig. 5).

\section{Discussion}

The influence of antecedent and initial soil surface conditions on hydrological response and soil erosion delivery was investigated considering different soil surface conditions and rainfall intensities. Additionally, the H-R model was used to predict the experimental results. Here, the observed experimental results, the model application over the course of the rainfall events, as well as the predicted parameters, are discussed.

\subsection{Effect of the antecedent conditions on the hydrological response and soil erosion rate}

The initial moisture content influences the hydrological response on short time scales and consequently the initial soil erosion delivery. The initial hydraulic conductivity and the infiltration rate (which is controlled mainly by hydraulic conductivity and sorptivity, e.g., Barry et al., 1993, 2009) played a crucial role on the discharge rate and its timing, which in turn affect the soil erosion production. For instance, during E1, the time-to-runoff of flumes 1 and 2 were 14.3 and $27.1 \mathrm{~min}$, respectively. However, the time-to-runoff during the rest of the events was less than 3 min for both flumes (Table 1). When the soil surface was initially dry, freshly hand-cultivated and disaggregated, the infiltration rate is greater from the onset of rainfall, retarding the time-toponding and runoff (event E1) compared with experiments that were conducted on initially wet and compacted soils (events E2-4). Of course, for the same initial conditions, the hydrological response is controlled by the rainfall intensity. Additionally, the results showed that surface compaction affects the soil erosion behaviour, particularly the early peak. The initial conditions 
affect the maximum of the early peak and its timing, as well as the decline to steady-state.

Comparing events E1 and E4, which were carried out using the same precipitation rate $\left(28 \mathrm{~mm} \mathrm{~h}^{-1}\right)$, but with different initial moisture content and soil compaction (Table 1), the timing of the sediment peak and the time needed to achieve steady-state behaviour differed markedly. For event E1, the peak observed with bare soil increased gradually to a maximum about 10 min after runoff began, then declined gradually to steady state. Steady state was, however, not reached for the larger size classes, even after $2 \mathrm{~h}$ of rainfall (Fig. 2). For the corresponding flume during E4, the early peak was reached faster, about 4 min from the onset of runoff, and then declined rapidly towards steady-state after a further 12 min (Fig. 5). In event E1, the water depth increased gradually due to the high infiltration rate on the dry and freshly hand-cultivated soil (Fig. 1). Since raindrop detachment is reduced when the soil surface is protected by the overland water, the initial soil condition delayed this reduction (Jomaa et al. 2010). Different behaviour was evident for E4, for which the initial conditions (wetted and sealed due to the prior events) led rapidly to a higher surface water depth, which attenuated raindrop detachment after runoff was initiated. In other words, the most important change between E1 and E4 was the soil compaction, which reduced the hydraulic conductivity and consequently the infiltration rate. The latter was higher during E1, delaying the hydrological response (time-to-runoff and discharge rate), which in turn delayed the soil erosion delivery. During E4, however, the hydraulic conductivity was much lower enhancing the runoff and the water depth attenuating further the raindrop detachment and reducing the soil erosion rate. Previous studies showed that sediment peak size depends on the ratio of water depth to raindrop diameter (Fujiwara et al. 1986; Rose et al. 1983b). Fujiwara et al. (1986) reported that the detachability of the original soil is a concave function of the water depth to raindrop diameter ratio, with a maximum in the range 1.5-2 depending on the size class. Assuming that the sprinkler system generates raindrops with uniform size ( $2.2 \mathrm{~mm}$, Tromp-van Meerveld et al., 2008), the relation of sediment peak and ratio is then only controlled by surface water depth (other factors 
being equal).

Repeated wetting-drying of the soil surface alters aggregate stability and, consequently, soil erosion delivery. This complicates process-based soil erosion understanding and prediction. Results showed that resistance to raindrop detachment varies between successive events, reflecting the effect of wetting-drying cycles, surface sealing and crusting, as well as soil erosion impacts on the soil surface that occurred during the preceding events. Kuhn and Bryan (2004) reported that soil loss usually decreased during successive storms due to the development of a cohesive crust formed during the initial storm, which decreased the amount of easily detachable sediment available for raindrop detachment during subsequent storms. The formation of surface sealing due to raindrop impact increases the soil cohesion and decreases the infiltration rate, which in turn reduce the time-to-ponding and the overland flow depth, with a marked reduction of detachability (Assouline, 2004; Poesen and Savat, 1981).

\subsection{Effect of a rock fragment cover on the evolution of steady-state infiltration rate through multiple rainfall events}

The evolution of the steady-state infiltration rates between flumes 1 and 2 through the multiple rainfall events differed markedly (Table 1). For bare soil conditions, the steady-state infiltration was $7.5 \mathrm{~mm} \mathrm{~h}^{-1}$ for event $\mathrm{E} 1$ and $2.6 \mathrm{~mm} \mathrm{~h}^{-1}$ for event $\mathrm{E} 2$. It appears that a nearly constant value ranging from 1.5-2 $\mathrm{mm} \mathrm{h}^{-1}$ was reached during the following two events, i.e., at the end of E2 soil sealing/compaction was completed. However, for the rock fragment-covered flume the steadystate value declined linearly over the four events. Surface sealing in flume 2 is likely similar between the rock fragments. However, the areas beneath the latter are protected, hence there is probably little change in the hydraulic conductivity there. Thus, the reduction in hydraulic conductivity in areas exposed to raindrops is responsible for the average linear decrease in the infiltration rate. Additionally, the surface rock fragments increased the water depth development 
due to the reduction of area cross-sectional area available for flow, which produced increased infiltration relative to the bare flume. Increased infiltration has been shown to reduce soil erosion from raindrop impact (Walker et al., 2007). Of course, our findings are based on only a single rock fragment coverage (40\%), using a specific placement method (on the soil surface). Thus, to generalize the effects of rock fragments on multiple rainfall events, further investigations varying the rock fragment characteristics (size, location, placement method and coverage) - are recommended.

\subsection{H-R modelling}

The area-adjusted H-R model was used to predict the observed sediment yields. The model did not predict the experimental results collected from the four events with the same estimated parameter values due to the evolution of soil surface properties. However, when four different sets of parameters were used (Table 4) the model was able to predict the individual sediment yields collected from each event, although with different degrees of accuracy. The quality of the model's predictions differed between erosion events (Figs. 2-5). The detachability of the original soil, $a$, decreased linearly throughout the rainfall events for both flumes, possibly due to the combined effects of drying between events and soil compaction induced by raindrops (Table 4). The $a$ values obtained for bare soil conditions were greater than for the rock fragment-protected flume. The detachability of the deposited layer, $a_{d}$, reduced similarly between flumes 1 and 2 , through the sequence of rainfall events (Table 4), except that it was reduced further during E2 for the rock fragment-covered flume. The change of $a_{d}$ between events suggests that this parameter is controlled by whether steady-state conditions were reached in the previous event. Where steady state was not reached (E1 for bare soil conditions), the value of $a_{d}$ was higher for the events where steady-state behaviour was quickly achieved, i.e., at the onset of runoff (for all other events, Table 4). We suggest that the drying of the seal after the first event E1 reduced the erodibility of the 
deposited layer, hence the lower $a_{d}$ value during the next events (E2, H3 and E4). The evolution of the mass per unit area needed to shield the deposited layer, $m_{t}^{*}$, through the erosive events seems mainly controlled by the rainfall intensity (Table 4). From the value of $m_{t}^{*}$, the average thickness of the shield layer $(z)$ was determined for each rainfall event (Table 4). These estimated values are nonphysical since they have the same order of magnitude as the grain size. These findings are in agreement with those of Jomaa et al. (2012c).

Our simulations showed that the model is more dependent to the value of $a$ than to the other parameters $\left(a_{d}\right.$ and $\left.m_{t}^{*}\right)$. The H-R model uses a simplified picture of suspended sediment ignoring other mechanisms influencing soil yields such as the soil morphological heterogeneity, the impulsive ejection of particles due to the direct impact of raindrops, and non-suspended load transport processes such as saltation and rolling. The model assumptions are well described elsewhere (Jomaa et al., 2012c; Tromp-van Meerveld et al., 2008). For the very shallow depths existing at the initial stage of an erosive event, high sediment yields occur due to the raindrop splash, which affect settling velocities due to particle interactions (Baldock et al., 2004). Accordingly, as with Jomaa et al. (2010, 2012c) and Tromp-van Meerveld et al. (2008), the measured settling velocities were used only for the four finest size classes; however, they were reduced for the larger size classes (larger than $100 \mu \mathrm{m})$. Thus, the settling velocity does not represent the motion of larger particles, which likely move preferentially via rolling and saltation rather than suspended in water (e.g., Asadi et al., 2007). Infiltration directly affects the deposition rate by enhancing the downward flow component of the water velocity, which effectively increases the settling velocities of size classes reducing the soil erosion (Walker et al., 2012). This could explain the higher settling velocity values used in event E1 for both flumes and for flume 1 during E2 (Table 3). For these flume experiments, the surface sealing was not fully developed and infiltration was greater than in the other experiments. Over the course of the experiments, 
infiltration reduced significantly due to the soil sealing. For events E1, E3 and E4, the same settling velocities were applied to both flumes, whereas for E2 different settling velocities were used in each, reflecting the different soil conditions in each flume at the end of event E1.

Jomaa et al. (2012c) reported that only when the steady-state effluent fractions were used instead of the size fractions of the original soil - was the model able to predict the sediment yields of the individual size classes (Table 2). Previously, it was found that, at steady-state, the effluent sediment yields tend towards the original soil grain-size's distribution (Moss and Green, 1983; Proffitt et al., 1991; Tromp-van Meerveld et al., 2008; Walker et al., 1979). However, for the rainfall sequence reported in this work, the steady-state effluent sediment yields were different from the original soil proportions for both flumes (with and without rock fragments), being enriched in the finer sediment classes. Looking at the three first events E1-E3, the results show that there is a trend towards the original soil grain-size distribution (Table 2). From event E1 to event E3, the proportion of the finer particles decreased gradually, and consequently that of the larger size classes increased. By the end of event E3, the measured proportions of the two largest size classes $(315-1000$ and $>1000 \mu \mathrm{m})$ were about $10 \%$ smaller than in the original soil, suggesting that these classes only partly contributed to the erosion event. Proportionally, this leads to an increased contribution of the mid-size classes $(2-20$ and $20-50 \mu \mathrm{m})$. For the remaining classes, at steady-state, the same proportion measured in the original soil was found. The measured sediment effluent yields during event E4 were enriched in finer materials and depleted in coarse fractions, reflecting the complete development of the surface sealing and shield layer during the preceding events.

\section{Conclusions}

Four rainfall erosion events on successive days were carried out to study the influence of antecedent and initial soil conditions (surface sealing, wetting-drying cycles, and initial moisture 
content) on the soil erosion dynamics and hydrological response using laboratory flume experiments. Additionally, the degree to which this influence could be controlled by specific rock fragment coverage $(40 \%)$ was investigated. The experimental design was such that, between the first and second experiments, some (finer) sediment size classes exhibited steady-state effluent erosion yields, while others were still undergoing changes (i.e., were not at steady state). This behaviour is consistent with a fundamental prediction of the H-R model, i.e., that sediment size classes have different rates of evolution. Of course, the erosion of each size class is not independent of that of the other classes, so the attainment of steady state depends on the evolution of all classes. The time scale needed to reach steady state is controlled by the slowest evolving class, i.e., the largest particles. Even so, our results in the first rainfall event show that the finer class sizes reach steady state (in an operational sense) sooner than larger classes.

The results show that the soil erosion short-time response is mainly controlled by the initial conditions, whereas the long-time behaviour is controlled by the precipitation rate only, other factors being equal (antecedent moisture content, bulk density and surface roughness). When steady-state conditions were reached for all size classes (as for the second rainfall event), the next event produced sediment yields of the individual size classes that peaked rapidly, and then declined gradually to steady state. The initial peak was attributed to soil surface changes occurring during drying. In contrast, when steady-state was not achieved at the end of the previous experiment, different behaviour was observed. The early peak appeared only for the finer sediment size classes (that previously reached steady-state), but not for larger size classes. The larger sediment size classes, instead, evolved more irregularly towards their steady values. The presence of rock fragments cover on the soil surface, however, generated a rapid increase to a sediment yield peak, followed by a decline to steady-state sediment yield consistently for all size classes, behaviour that was in marked contrast to the bare soil conditions. This can be explained by a reduced cross-sectional area due to the surface rock fragments, increasing further the water 
depth and consequently attenuating raindrop detachment and reducing the time needed to reach steady-state (compared with bare soil). However, the effects of surface rock fragments should be considered in further experiments as only one specific setup (40\% surface coverage, fragments placed on the soil surface) was investigated in these experiments.

When the steady-state sediment yield was reached at the end of the previous event, and with similar precipitation, individual size classes consistently showed an early peak that rapidly declined to steady-state values. Overall, we found that, at the level of individual sediment size classes, short time erosion depends on whether steady conditions were achieved prior to the rainfall event. Independent of the initial conditions, the sediment yields tend to the same steady state value. If the initial conditions are specified incorrectly, it follows that predictions of cumulative soil erosion will be affected.

The modified H-R erosion model, taking the rock fragment cover into account, was used to predict the measured sediment yields. The model simulated the measured sediment yields reasonably well in situations where the shield layer and the surface sealing were rapidly and fully developed during the erosion event, or had been achieved previously. However, the model did not predict the details of measured sediment yields when quasi-steady conditions were maintained; such situations required a longer time to achieve soil compaction and to reach complete surface sealing development. The model does not account for these factors. Therefore, the H-R model is more applicable for predicting soil erosion from soils not undergoing compaction.

\section{Acknowledgment}

This work was supported by the Swiss National Science Foundation (Grants 200021-113815 and 200020-132544/1). 


\section{References}

Asadi, H., Ghadiri, H., Rose, C.W., Rouhipour, H., 2007. Interrill soil erosion processes and their interaction on low slopes. Earth Surf. Proc. Land., 32, 711-724.

Assouline, S., 2004. Rainfall-induced soil surface sealing: A critical review of observations, conceptual models, and solutions. Vadose Zone J. 3, 570-591.

Baldock, T.E., Tomkins, M.R., Nielsen, P., Hughes, M.G., 2004. Settling velocity of sediments at high concentrations. Coast. Eng. 51, 91-100.

Baril, P., 1991. Erodibilité des sols et érodabilité des terres: Application au plateau vaudois. Ph.D. Thesis, Ecole Polytech. Féd. Lausanne (EPFL), Lausanne, Switzerland, 218 pp., doi:10.5075/epfl-thesis-940.

Barry, D.A., Parlange, J.-Y., Sander, G.C., Sivaplan M., 1993. A class of exact solutions for Richards' equation. J. Hydrol. 142, 29-46.

Barry, D.A., Sander, G.C., Jomaa, S., Heng, B.C.P., Parlange, J.-Y., Lisle, I.G., Hogarth, W.L., 2010. Exact solutions of the Hairsine-Rose precipitation-driven erosion model for a uniform grain-sized soil. J. Hydrol. 389, 399-405.

Barry, D.A., Wissmeier, L., Parlange, J.-Y., Sander, G. C., Lockington, D.A., 2009. Comment on “An analytic solution of capillary rise restrained by gravity" by N. Fries and M. Dreyer. J. Colloid Interface Sci. 338, 293-295.

Beuselinck, L., Hairsine, P., Sander, G.C., Govers, G., 2002. Evaluating a multiclass net deposition equation in overland flow conditions. Water Resour. Res. 38, 1109, doi:10.1029/2001WR0000250.

Bryan, R.B., 2000. Soil erodibility and processes of water erosion on hillslope. Geomorphology. 
$32,385-415$.

Fohrer, N., Berkenhagen, J., Hecker, J.M., Rudolph, A., 1999. Changing soil and surface conditions during rainfall single rainstorm/subsequent rainstorms. Catena 37, 355-375.

Fujiwara, T., Fukada, M., Matsuzaki, H., 1986. The experimental study on the model of soil erosion by the impact of raindrops. Technol. Rep. Yamaguchi Univ. 3, 417-426.

Hairsine, P.B., Rose, C.W., 1991. Rainfall detachment and deposition: Sediment transport in the absence of flow-driven processes. Soil Sci. Soc. Am. J. 55, 320-324.

Hancock, G.R., Crawter, D., Fityus, S.G., Chandler, J., Wells, T., 2008. The measurement and modelling of rill erosion at angle of repose slopes in mine spoil. Earth Surf. Proc. Land. $33,1006-1020$.

Heng, B.C.P., Sander, G.C., Armstrong, A., Quinton, J.N., Chandler, J.H., Scott, C.F., 2011. Modeling the dynamics of soil erosion and size-selective sediment transport over nonuniform topography in flume-scale experiments. Water Resour. Res. 47, W02513, doi:10.1029/2010WR009375.

Heng, B.C.P., Sander, G.C., Scott C.F., 2009. Modeling overland flow and soil erosion on nonuniform hillslopes: A finite volume scheme. Water Resour. Res. 45, W05423, doi:10.1029/2008WR007502.

Hogarth, W.L., Rose, C.W., Parlange, J.-Y., Sander, G.C., Carey, G., 2004. Soil erosion due to rainfall impact with no inflow: A numerical solution with spatial and temporal effects of sediment settling velocity characteristics. J. Hydrol. 294, 229-240.

Jomaa, S., 2012a. Process-based precipitation-driven soil erosion modeling: Laboratory flume experiments and analysis with the Hairsine-Rose model, Ph.D. Thesis, Ecole Polytech. 
Féd. Lausanne (EPFL), Lausanne, Switzerland, 200 pp., doi:10.5075/epfl-thesis-5340.

Jomaa, S., Barry, D.A., Brovelli, A., Heng, B.C.P., Sander, G.C., Parlange, J.-Y., Rose, C.W., 2012b. Rain splash soil erosion estimation in the presence of rock fragments. Catena 92 , $38-48$.

Jomaa, S., Barry, D.A., Brovelli, A., Sander, G.C., Parlange, J.-Y., Heng, B.C.P., Tromp-van Meerveld, H.J., 2010. Effect of raindrop splash and transversal width on soil erosion: Laboratory flume experiments and analysis with the Hairsine-Rose model. J. Hydrol. 395, $117-132$.

Jomaa, S., Barry, D.A., Heng, B.C.P., Brovelli, A., Sander, G.C., Parlange, J.-Y., 2012c. Influence of rock fragment coverage on soil erosion and hydrological response: Laboratory flume experiments and modeling. Water Resour. Res. 48, W05535, doi:10.1029/2011WR011255.

Kuhn, N.J., Armstrong, E.K., Ling, A.C., Connolly, K.L., Heckrath, G., 2010. Interrill erosion of carbon and phosphorus from conventionally and organically farmed Devon silt soils. Catena 91, 94-103.

Kuhn, N.J., Bryan, R.B., 2004. Drying, soil surface condition and interrill erosion on two Ontario soils. Catena 57,113-133.

Le Bissonnais, Y., Benkhadra, H., Chaplot, V., Fox, D., King, D., Daroussin, J., 1998. Crusting, runoff and sheet erosion on silty loamy soils at various scales and upscaling from $\mathrm{m}^{2}$ to small catchments. Soil Tillage Res. 46, 69-80.

Le Bissonnais, Y., Bruand, A., Jamagne, M., 1989. Laboratory experimental study of soil crusting: Relation between aggregate breakdown mechanisms and crust structure. Catena 16, $377-392$. 
Le Bissonnais, Y., Singer, M.J., 1992. Crusting, runoff, and erosion response to soil water content and successive rainfalls. Soil Sci. Soc. Am. J. 56, 1898-1903.

Legout, C., Leguédois, S., Le Bissonnais, Y., 2005. Aggregate breakdown dynamics under rainfall compared with aggregate stability measurements. Eur. J. Soil Sci. 56, 225-237.

Lisle, I.G., Rose, C.W., Hogarth, W.L., Hairsine, P.B., Sander, G.C., Parlange, J.-Y., 1998. Stochastic sediment transport in soil erosion. J. Hydrol. 204, 217-230.

Loosvelt, L., 2007. Scale dependent influence of rock fragment cover on soil infiltration, runoff and sediment yield in arid zones of Chile. Ph.D. Thesis, Universiteit Gent, Gent, Belgium, $155 \mathrm{pp}$.

Luk, S.H., Cai, Q.G., Wang, G.P., 1993. Effects of surface crusting and slope gradient on soil and water losses in the hilly loess region, north China. Catena Suppl. 24, 29-45.

Mamedov, A.I., Huang, C., Levy, G.J., 2006. Antecedent moisture content and aging duration effects on seal formation and erosion in smectitic soils. Soil Sci. Soc. Am. J. 70, 832-843.

Mazurak, A.P., Mosher, P.N., 1968. Detachment of soil particles in simulated rainfall. Soil Sci. Soc. Am. J. 32, 716-719.

Moss, A.J., Green, P., 1983. Movement of solids in air and water by raindrop impact. Effects of drop-size and water-depth variations. Aust. J. Soil Res. 21, 257-269.

Neave, M., Rayburg, S., 2007. A field investigation into the effects of progressive rainfall-induced soil seal and crust development on runoff and erosion rates: The impact of surface cover. Geomorphology 87, 378-390.

Parlange, J.-Y., Hogarth, W.L., Rose, C.W., Sander, G.C., Hairsine, P., Lisle, I., 1999. Addendum 
to unsteady soil erosion model. J. Hydrol. 217, 149-156.

Poesen, J., Ingelmo-Sanchez, F., Mucher, H., 1990. The hydrological response of soil surfaces to rainfall as affected by cover and position of rock fragments in the top layer. Earth Surf. Proc. Land. 15, 653-671.

Poesen, J., Savat, J., 1981. Detachment and transportation of loose sediments by raindrop splash: Part II. Detachability and transport ability measurements. Catena 8, 19-41.

Poesen, J., Torri, D., Bunte, K., 1994. Effects of rock fragments on soil erosion by water at different spatial scales: A review. Catena 23, 141-166.

Proffitt, A.P.B., Rose, C.W., Hairsine, P.B., 1991. Rainfall detachment and deposition: Experiments with low slopes and significant water depths. Soil Sci. Soc. Am. J. 55, 325-332.

Rieke-Zapp, D., Poesen, J., Nearing, M.A., 2007. Effects of rock fragments incorporated in the soil matrix on concentrated flow hydraulics and erosion. Earth Surf. Proc. Land. 32, $1063-1076$.

Rimal, B.K., Lal, R., 2009. Soil and carbon losses from five different land management areas under simulated rainfall. Soil Tillage Res. 106, 62-70.

Römkens, M.J.M., Helming, K., Prasad, S.N., 2002. Soil erosion under different rainfall intensities, surface roughness, and soil water regimes. Catena 46, 103-123.

Rose, C.W., Williams, J.R., Sander, G.C., Barry, D.A., 1983a. A mathematical model of soil erosion and deposition processes: I. Theory for a plane land element. Soil Sci. Soc. Am. J. 47, 991-995. 
Rose, C.W., Williams, J.R., Sander, G.C., Barry, D.A., 1983b. A mathematical model of soil erosion and deposition processes: II. Application to data from an arid-zone catchment. Soil Sci. Soc. Am. J. 47, 996-1000.

Rose, C.W., Yu, B., Ghadiri, H., Asadi, H., Parlange, J.-Y., Hogarth, W.L., Hussein, J., 2007. Dynamic erosion of soil in steady sheet flow. J. Hydrol. 333, 449-458.

Rudolph, A., Helming, K., Diestel, H., 1997. Effect of antecedent soil water content and rainfall regime on microrelief changes. Soil Technol. 10, 69-81.

Sander, G.C., Hairsine, P.B., Rose, C.W., Cassidy, D., Parlange, J.-Y., Hogarth, W.L., Lisle, I.G., 1996. Unsteady soil erosion model, analytical solutions and comparison with experimental results. J. Hydrol. 178, 351-367.

Sander, G.C., Parlange, J.-Y., Barry, D.A., Parlange, M.B., Hogarth, W.L., 2007. Limitation of the transport capacity approach in sediment transport modeling. Water Resour. Res. 43, W02403, doi:10.1029/2006WR00517.

Singer, M.J., Shainberg, I., 2004. Mineral soil surface crusts and wind and water erosion. Earth Surf. Proc. Land. 29, 1065-1075.

Tromp-van Meerveld, H.J., Parlange, J.-Y., Barry, D.A., Tromp, M.F., Sander, G.C., Walter, M.T., Parlange, M.B., 2008. Influence of sediment settling velocity on mechanistic soil erosion modeling. Water Resour. Res. 44, W06401, doi:10.1029/2007WR006361.

Viani, J.-P., 1986. Contribution à l'étude expérimentale de l'érosion hydrique. Ph.D. Thesis, Ecole Polytech. Féd. Lausanne (EPFL), Lausanne, Switzerland, 239 pp., 10.5075/epfl-thesis-641.

Walker, P.H, Kinnell P.I.A., Green P., 1979. Transport of a noncohesive sandy mixture in rainfall and runoff experiments. Soil Sci. Soc. Am. J. 42, 793-801. 
Walker, J.D., Walter, M.T., Parlange, J.Y., Rose, C.W., Meerveld, H., Gao, B., Cohen, A.M., 2007. Reduced raindrop-impact driven soil erosion by infiltration. J. Hydrol. 342, $331-335$. 
Table 1. Summary of experiments. For each experiment, flume 1 contained bare soil. In flume 2, rock fragments were place on top of the soil.

\begin{tabular}{|c|c|c|c|c|c|c|c|c|c|}
\hline \multirow{2}{*}{ Event } & \multirow{2}{*}{ Flume } & \multirow{2}{*}{$\begin{array}{l}P^{\mathrm{A}} \\
\left(\mathrm{mm} \mathrm{h}^{-1}\right)\end{array}$} & \multicolumn{2}{|c|}{$M_{c}^{\mathrm{B}}(\%)$} & \multirow{2}{*}{$\begin{array}{l}R^{\mathrm{C}} \\
\left(\mathrm{mm} \mathrm{h}^{-1}\right)\end{array}$} & \multirow{2}{*}{$\begin{array}{l}C_{m}{ }^{\mathrm{D}} \\
\left(\mathrm{g} \mathrm{m}^{-1}\right)\end{array}$} & \multirow{2}{*}{$\begin{array}{l}C_{d}^{\mathrm{E}} \\
\left(1 \mathrm{~m}^{-1}\right)\end{array}$} & \multirow{2}{*}{$\begin{array}{l}t_{r}^{\mathrm{F}} \\
(\mathrm{min})\end{array}$} & \multirow{2}{*}{ Initial soil condition } \\
\hline & & & Initial & Final & & & & & \\
\hline \multirow{2}{*}{ E1 } & Bare soil & & 7.7 & 18.3 & 20.5 & 880.8 & 41.1 & 14.3 & \multirow{2}{*}{$\begin{array}{l}\text { Hand-cultivated, smoothe } \\
\text { and slightly pre-wetted }\end{array}$} \\
\hline & $40 \%$ cover & & 8.8 & 30.9 & 14.6 & 305.8 & 14.6 & 27.1 & \\
\hline \multirow{3}{*}{ E2 } & Bare soil & & 19.1 & 21.9 & 71.4 & 4626.4 & 237.4 & 1.3 & \multirow{9}{*}{$\begin{array}{l}\text { The soil was not altered } \\
\text { and left to air dry }\end{array}$} \\
\hline & & 74 & & & & & & & \\
\hline & $40 \%$ cover & & 24.8 & 29.5 & 63.8 & 2814.2 & 208.2 & 2.1 & \\
\hline \multirow{3}{*}{ E3 } & Bare soil & \multirow{3}{*}{74} & 20.4 & 22.0 & 72.0 & 4878.9 & 257.2 & 1.2 & \\
\hline & & & & & & & & & \\
\hline & $40 \%$ cover & & 25.2 & 29.8 & 67.9 & 2671.4 & 244.5 & 2.1 & \\
\hline \multirow{3}{*}{ E4 } & Bare soil & \multirow{3}{*}{28} & 22.1 & 22.6 & 26.8 & 616.5 & 82.5 & 1.6 & \\
\hline & & & & & & & & & \\
\hline & $40 \%$ cover & & 26.4 & 27.3 & 25.8 & 412.0 & 78.4 & 2.5 & \\
\hline
\end{tabular}

\footnotetext{
${ }^{\mathrm{A}}$ Precipitation rate

${ }^{\mathrm{B}}$ Soil volumetric moisture content

${ }^{\mathrm{C}}$ Steady-state runoff rate $(R=P-f$, where $f$ is the steady-state infiltration rate)

${ }^{D}$ Cumulative eroded mass measured in the collection point of each flume at the end of the experiment

${ }^{\mathrm{E}}$ Cumulative discharge measured in the collection point of each flume at the end of the experiment

${ }^{\mathrm{F}}$ Time-to-runoff
} 
Table 2. Particle size distribution of the original soil and of the eroded sediments discharged at steady-state from the two flumes and for the four precipitation events. The effluent fractions used here were determined as an average fraction from the last samples in each event, where steadystate was reached in each event (except E1).

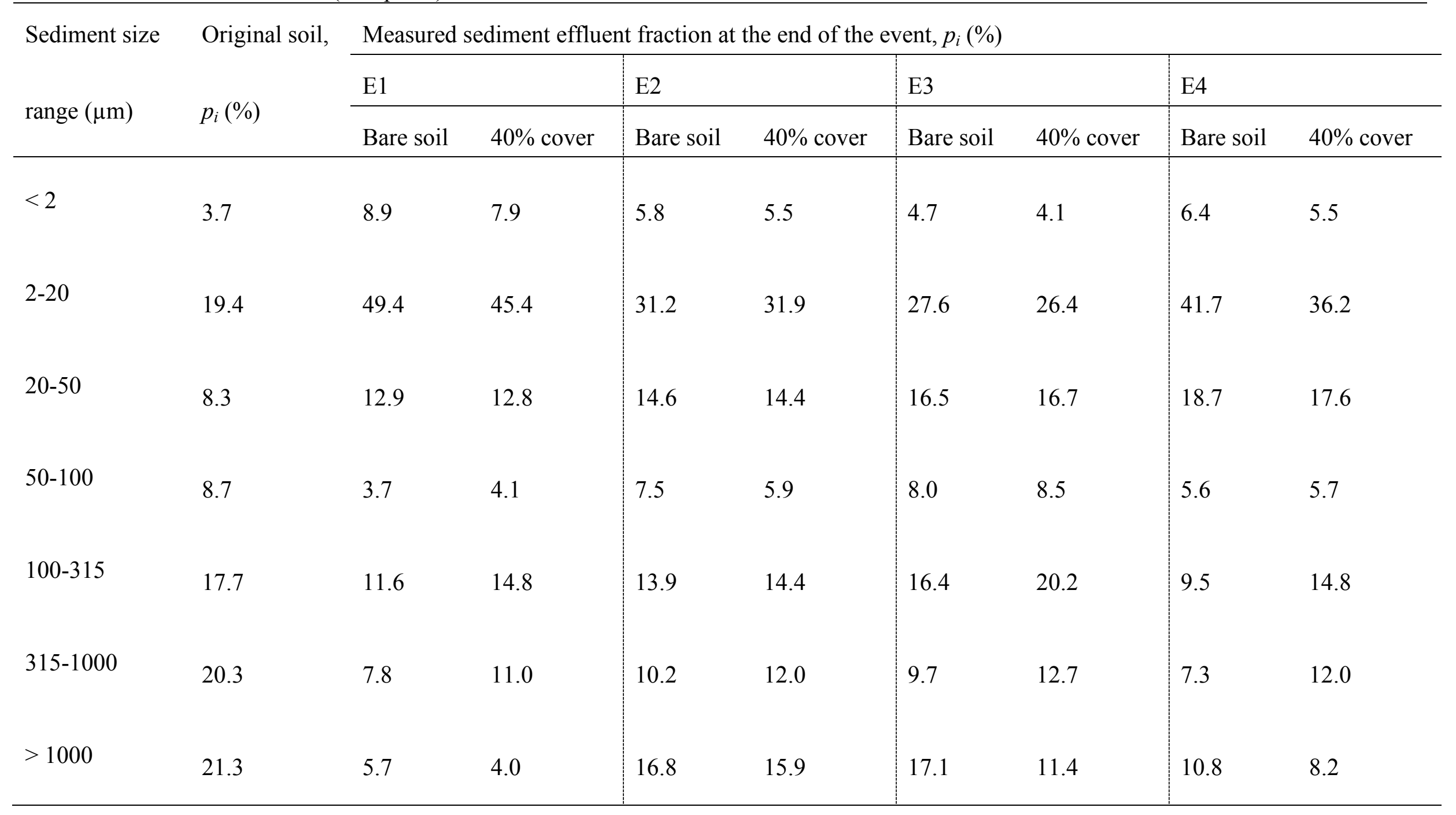


Table 3. Measured and calibrated settling velocities for the seven particle size classes considered in the modelling. Settling velocities were modified (reduced in most cases) to improve model fitting of the medium and coarse particle size classes.

\begin{tabular}{|c|c|c|c|c|}
\hline \multirow{2}{*}{$\begin{array}{l}\text { Sediment size } \\
\text { range }(\mu \mathrm{m})\end{array}$} & \multicolumn{2}{|c|}{ Measured $v_{i} \times 10^{-3}\left(\mathrm{~m} \mathrm{~s}^{-1}\right)^{\mathrm{A}}$} & \multicolumn{2}{|c|}{ Calibrated $v_{i} \times 10^{-3}\left(\mathrm{~m} \mathrm{~s}^{-1}\right)$} \\
\hline & From & To & Series $1^{\mathrm{B}}$ & Series $2^{C}$ \\
\hline$<2$ & 0.00008 & 0.004 & 0.00008 & 0.00008 \\
\hline $2-20$ & 0.004 & 0.4 & 0.004 & 0.004 \\
\hline $20-50$ & 0.4 & 2.5 & 0.8 & 0.4 \\
\hline $50-100$ & 2.5 & 14 & 80 & 0.5 \\
\hline $100-315$ & 14 & 37 & 40 & 0.3 \\
\hline $315-1000$ & 37 & 69 & 70 & 0.3 \\
\hline$>1000$ & 69 & 140 & 600 & 30 \\
\hline
\end{tabular}

\footnotetext{
${ }^{\mathrm{A}}$ Measured settling velocities taken from Tromp-van Meerveld et al. (2008).

${ }^{\mathrm{B}}$ Used for experiments E1 (flumes 1-2) and E2 (flume 1).
}

${ }^{\mathrm{C}}$ Used for experiments E2 (flume 2), E3 (flumes 1-2) and E4 (flumes 1-2). 
Table 4. Optimized parameters, overland flow depth $(D)$ and thickness of the deposited layer $(z)$ as well as the model evaluation index obtained after fitting the experimental data with the modified H-R model of Jomaa et al. (2012c). A graphical comparison of measurements and simulation results is given in Figs. 2-5.

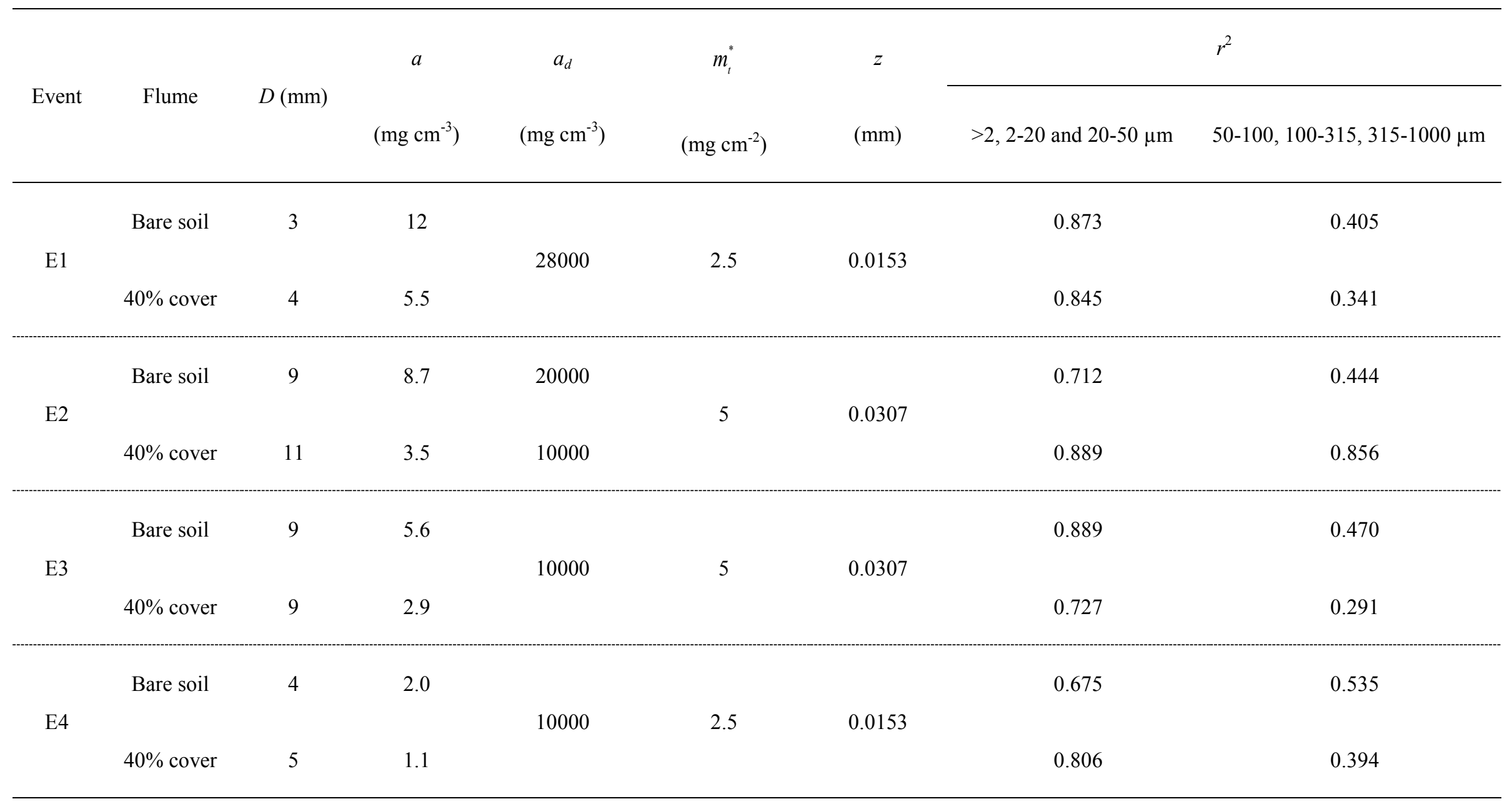



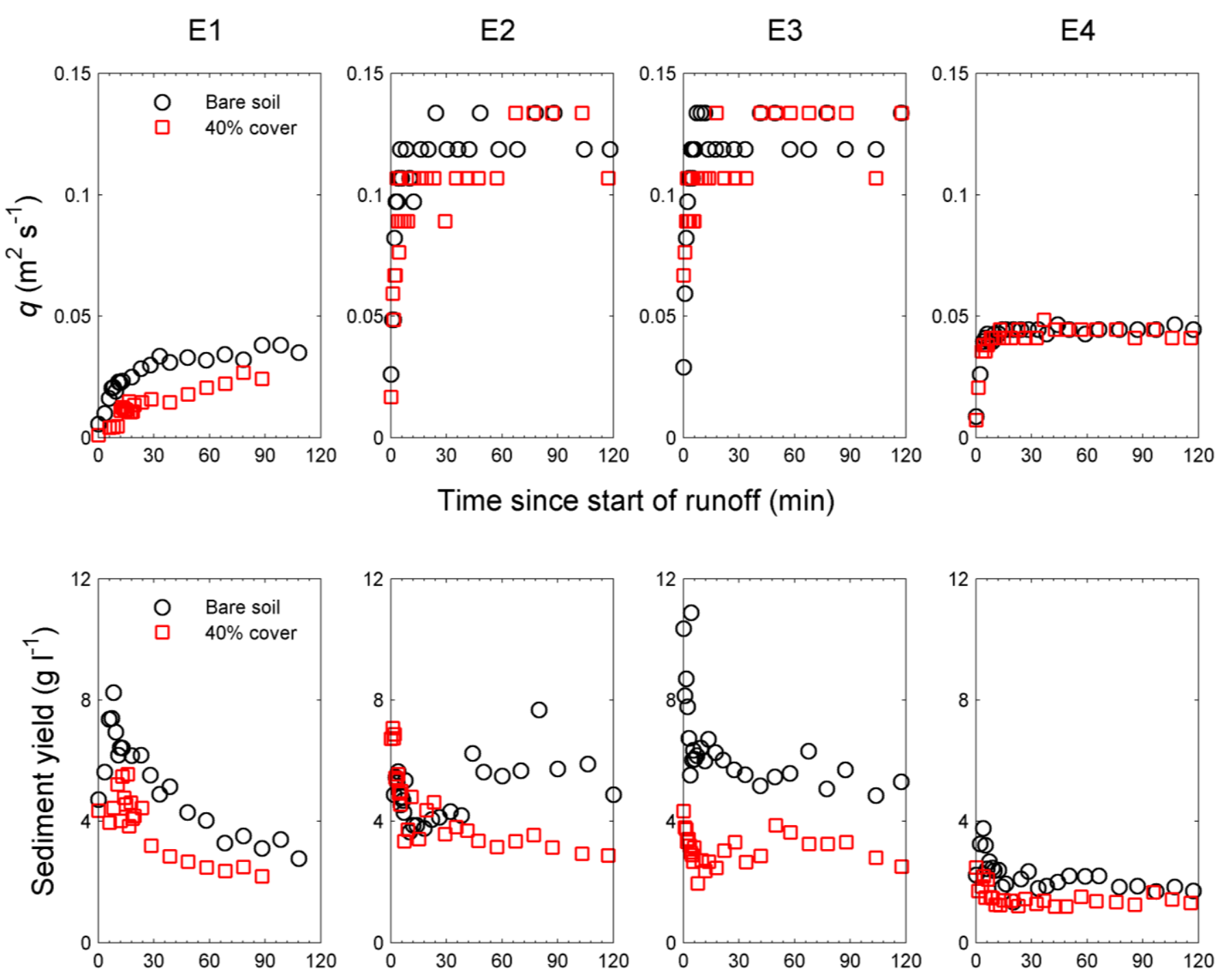
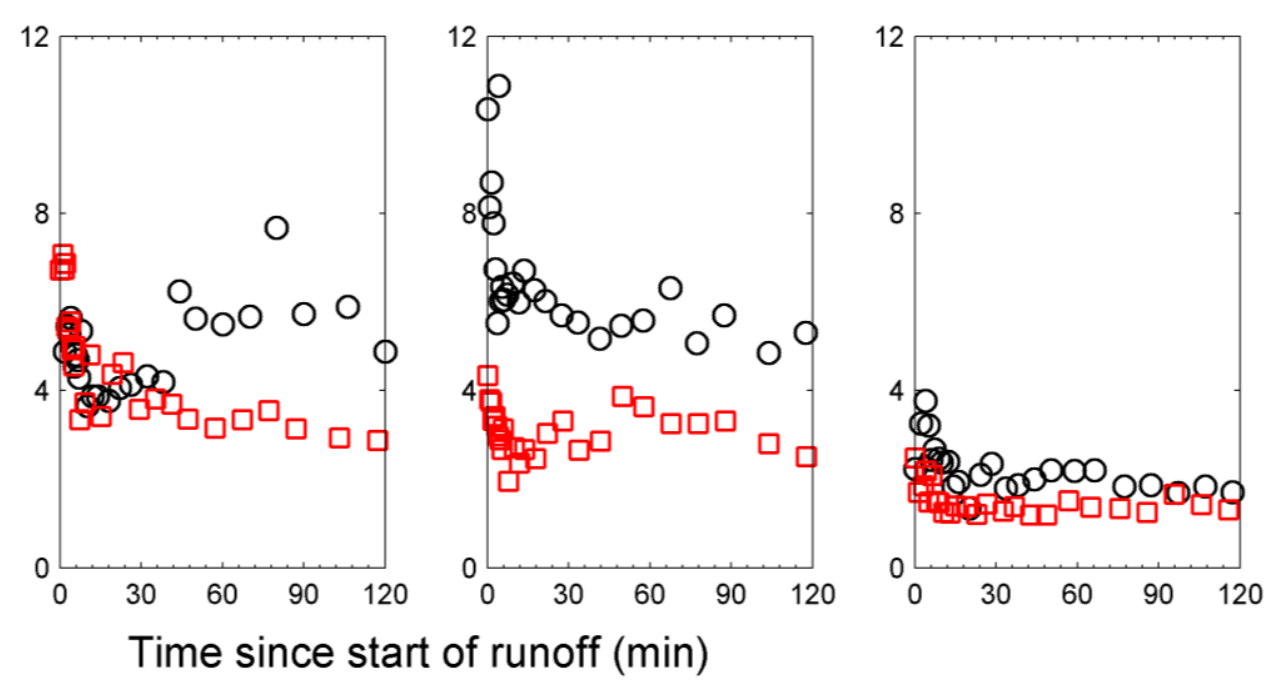

Fig. 1. Unit discharges, $q$ (top row), and total sediment yields (bottom row) of the four rainfall events as a function of time since start of runoff. For all experiments, data collected from flume 1 (bare soil) are plotted as black circles, while those of flume 2 (40\% rock fragment cover) are as red squares. 


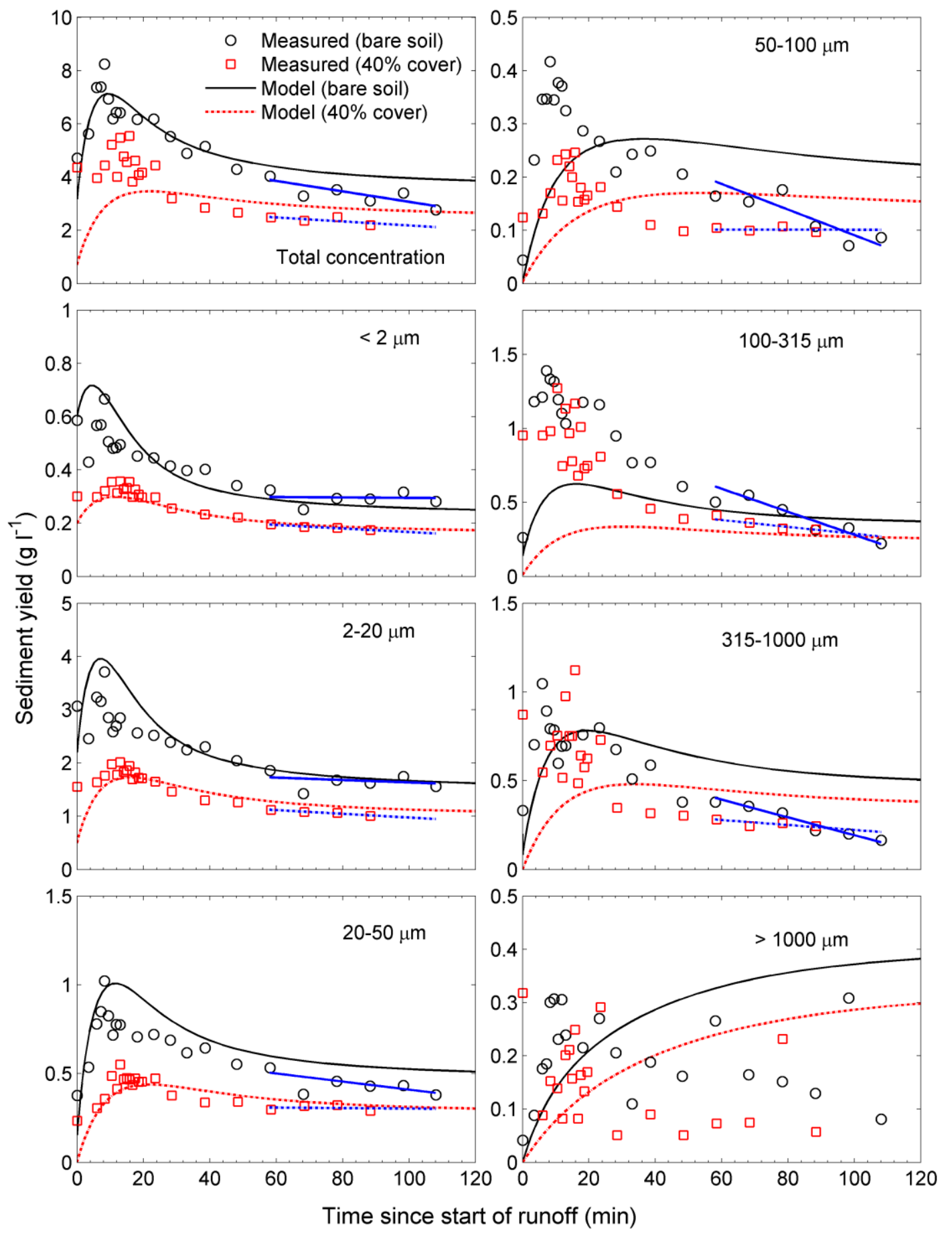

Fig. 2. Measured and simulated sediment yields for event E1 (modified from Jomaa et al., 2012c). In both flumes, the model reproduces well the observed behaviour only for the two finest size classes, while it under- or over- predicts the rest of classes. The blue lines (solid for flume 1, dashed for flume 2) show the sediment yield trend (determined by eye) of the measurements during the steady-state behaviour. 


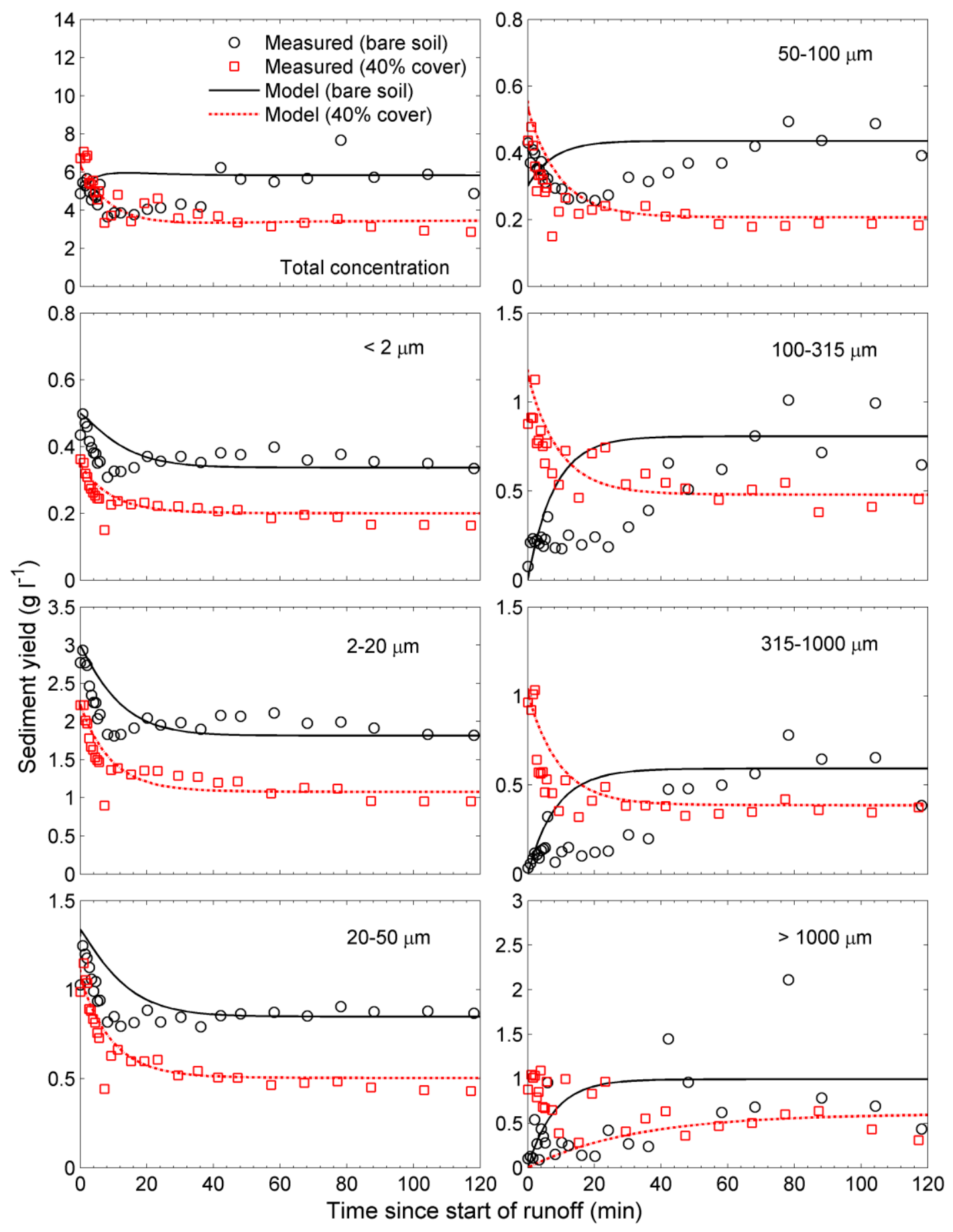

Fig. 3. Observed and simulated sediment yields for event E2. Different behaviour was found for the bare and rock fragment-covered soils. The H-R model reproduced well the patterns observed in the data - including all sediment classes and during the entire erosion duration - only for rock fragmentscovered flume. 


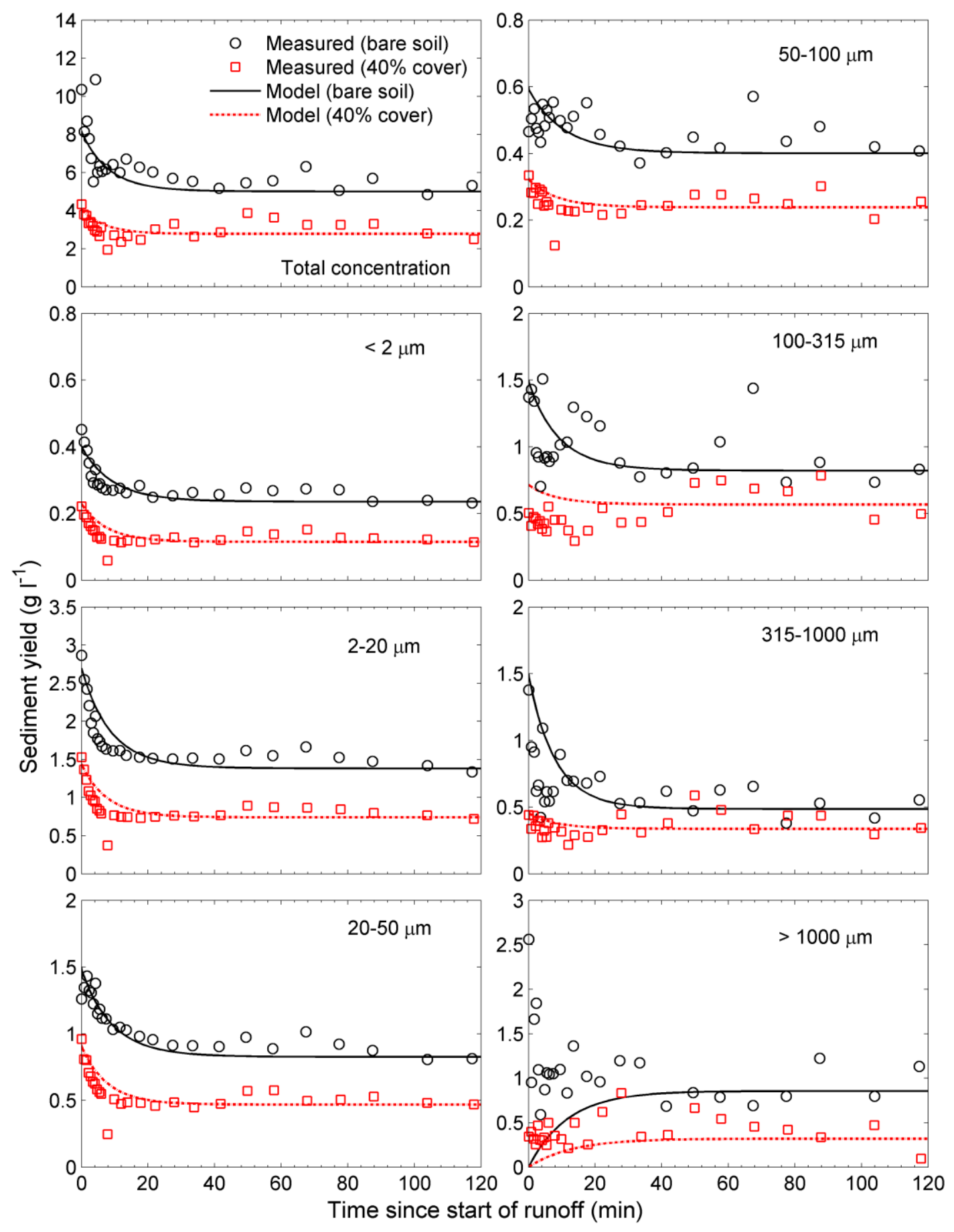

Fig. 4. Measured and modelled sediment yields for event E3. Although the same rainfall intensity was used, events E2 (Fig. 3) and E3 showed different behaviour, in particular for bare soil conditions. The modified H-R model reproduced the observations satisfactorily. 


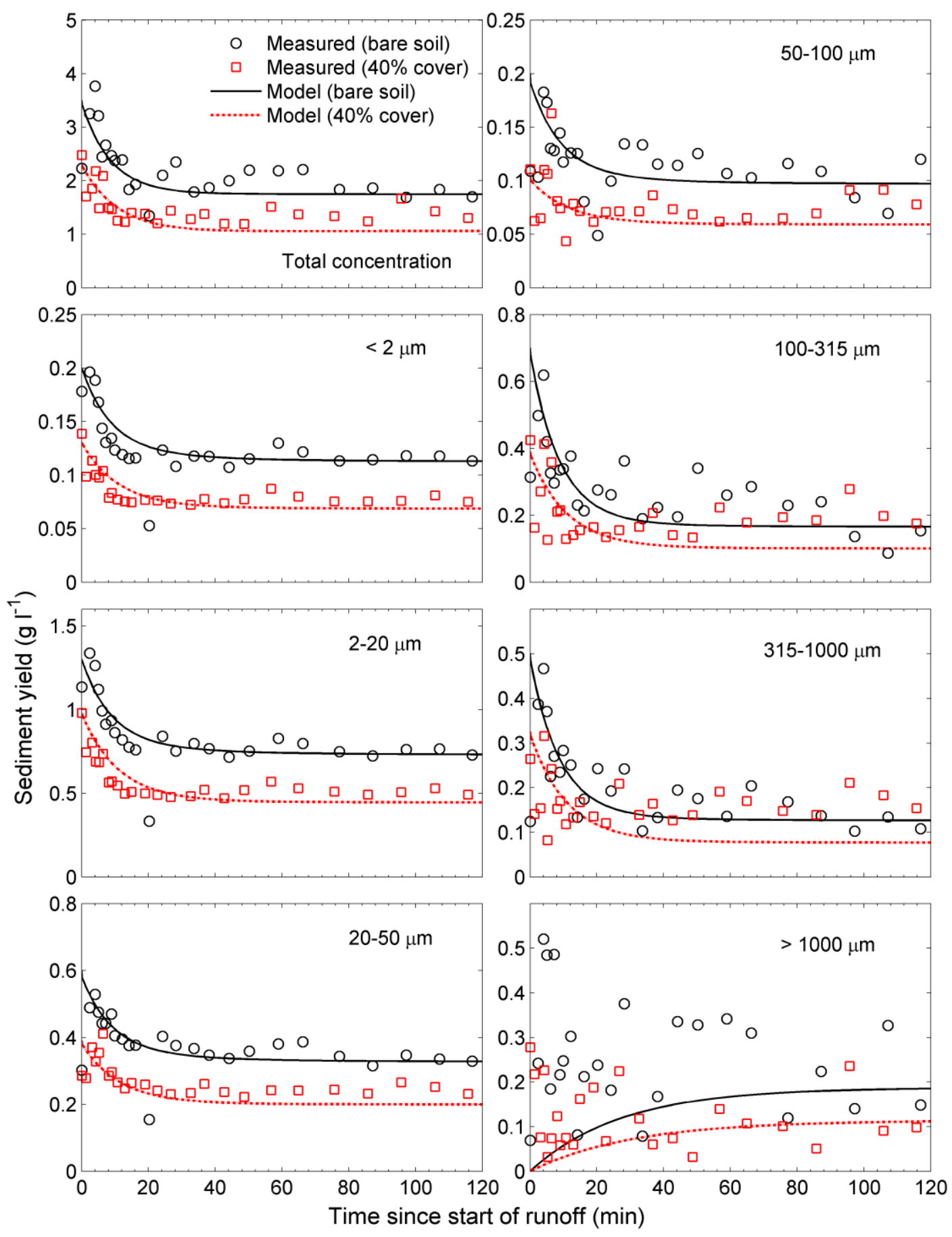

Fig. 5. Observed and simulated sediment yields for event E4. The erosion yields are reduced compared with those observed for E1, although the same rainfall rate was used, highlighting the importance of the soil's initial condition on erosion rates. Except for the largest size class, the modified H-R model was able to reproduce the observations reasonably well. 